\title{
Removal of volatile organic compounds from air using activated carbon impregnated cellulose acetate electrospun mats
}

\author{
Kashyap Patil ${ }^{1}$, Seonju Jeong ${ }^{2}$, Hankwon Lim², Hun-Soo Byun ${ }^{3}$, Sangil Han ${ }^{{ }^{+}}$ \\ ${ }^{1}$ Department of Chemical Engineering, Changwon National University, Changwon 51140, Republic of Korea \\ ${ }^{2}$ Department of Advanced Materials and Chemical Engineering, Catholic University of Daegu, Gyeongsan 38430, Republic of Korea \\ ${ }^{3}$ Department of Chemical and Biomolecular Engineering, Chonnam National University, Yeosu 59626, Republic of Korea
}

\begin{abstract}
Volatile organic compounds (VOCs) are released from various sources and are unsafe for human health. Porous materials are promising candidates for the adsorption of VOCs owing to their increased ratio of surface area to volume. In this study, activated carbon (AC) impregnated cellulose acetate (CA) electrospun mats were synthesized using electrospinning for the removal of VOCs from the air mixture of ACs, and CA solution was electrospun at different proportions $(5 \%, 10 \%$, and $15 \%)$ in a single nozzle system. The different AC amounts in the electrospun mats were distributed within the AC fibers. The adsorption capacities were measured for acetone, benzene, and dichloromethane, using quartz crystal microbalance. The results elicited an increasing adsorption capacity trend as a function of the impregnation of ACs in the electrospun mats, while their capacities increased as a function of the AC concentration. Dichloromethane resulted in a faster adsorption process than acetone and benzene owing to its smaller molecular size. VOCs were desorbed with the $\mathrm{N}_{2}$ gas purging, while VOCs were adsorbed at higher temperatures owing to the increased vapor pressures. The adsorption analysis using Dubinin-Astakhov equation showed that dichloromethane is more strongly adsorbed on mats.
\end{abstract}

Keywords: Activated carbon, Adsorption, Electrospinning, Quartz crystal microbalance, VOCs removal

\section{Introduction}

Volatile organic compounds (VOCs) are gaseous compounds associated with high vapor pressures at room temperature. Chemical processing industries involved with the manufacturing, handling, and the distribution of paints, lubricants, and liquid fuels, constitute the primary sources of VOCs [1]. These entities often leak from pipes, heat exchange systems, and processing vessel vents, and cause loading losses in storage tanks. VOCs are not only present in air but they are also the product of volatilization of building materials, detergents, pesticides, and cosmetics [2], which consist of liquid fuels, cleaning agents, lubricants, solvent thinners, and degreasers. Prolonged exposure to VOCs can potentially affect human health based on their effects on the central nervous system and liver, and can potentially lead to harmful and irritating effects on the eyes and throat [3].

The porous materials with increased internal surface areas up to $7,000 \mathrm{~m}^{2} / \mathrm{g}$ and with very small pores [4] are potential candidates for sensing and gas storage applications, separation, and catalysis [5]. Porous materials, such as zeolite, activated carbon (AC), and metal-organic framework (MOF) [4], have been used for the removal of VOCs in membrane processes, adsorption, and chromatographic separation. Das et al. [5] concluded that AC fibers are potential adsorbents for the removal of VOCs from the air, Chiang et al. [6] studied the effects of pore structure and temperature on the adsorption of VOCs on AC. Khan and Ghoshal [3] studied the VOC removal by zeolites from polluted air. In turn, Kim and Ahn [7] studied the adsorption properties of zeolites, like benzene, toluene, xylene, and methanol, using microwave heating (for desorption). Additionally, Yang et al. [8] reported the effects of the molecular size and the shape on the adsorption of gaseous VOCs by MOF MIL-101.

Electrospinning is a type of process that produces nanofibers using electrostatic force. Nanofibers produced by electrospinning possess a high-surface area owing to their interconnected structures. Polymer solution charged with a high-voltage power 
is ejected from the tip of the needle to a collector at a controlled flow rate when a repulsive electric force overcomes the surface tension. The solution jet is converted to a solid fiber while travelling from the needle to the collector [9, 10]. Accordingly, fiber morphology can be influenced by many parameters relevant to solution properties (viscosity, elasticity, conductivity, and surface tension) [11], process parameters (electric potential, flow rate, concentration, and the distance between the capillary and collector), and ambient parameters (temperature, humidity, and air velocity). The electrospinning techniques have been applied to produce adsorbents for VOC removal. Shim et al. [12] found that electrospun polyacrylonitrile (PAN) mats were effective for the removal of VOCs owing to their shallow pore structures [13]. However, Scholten et al. [14] demonstrated that polyurethane solutions can be electrospun to produce fiber mats to adsorb acetone and toluene depending on the building blocks used in fiber synthesis with high-adsorption capacities. Feng et al. [11] studied chloroform removal by membrane gas stripping using electrospun polyvinylidene fluoride (PVDF) nanofiber membranes. Additionally, electrospun mats were used for other separation processes, such as thermoregulated gas transport [15], particulate matter filtration, and seawater desalination [16], which mainly depends on the large surface area of the electrospun mats. In general, as the specific area increased, the separation properties improved.

Condensation, thermal oxidation, catalytic oxidation, absorption, adsorption, and many other techniques are used to control the concentration of VOCs in the air $[5,17]$. Among these, adsorption has been used during the past several years in bulk separation or purification processes, and was found to be effective at low-concentration levels (in ppm) [18]. Zhou et al. enhanced the VOC adsorption capacity using porous composites. They prepared ZIF-8 and graphene oxide composites to study the adsorption of VOCs. They showed an enhancement in the adsorption capacity following increases of graphene oxide content [19]. In other studies, Liu et al. investigated the adsorption of trichloroethylene and benzene vapors onto hyper crosslinked polymeric resins [20]. Goss and Eisenreich studied the adsorption of VOCs from the gas phase onto various minerals and mineral mixtures [21].

In the present work, we used AC powders with a specific surface area up to $2,000 \mathrm{~m}^{2} / \mathrm{g}$ to increase the adsorption capacities of electrospun fiber mats. A solution mixture of cellulose acetate (CA) and AC powder was electrospun to produce CA fiber mats impregnated with AC particles. Given that quartz crystal microbalance (QCM) has elicited significant improvements for online and in situ detection of VOCs in comparison to conventional detection techniques, including gas chromatography, mass spectrometry, and Fourier transform infrared spectroscopy [22], the adsorption performance of the mats was evaluated by the QCM system which can measure the real time data of the adsorption and desorption of VOCs. In this study, acetone, benzene, and dichloromethane, were used as model VOCs. These compounds are extensively used in manufacturing at varying temperatures and concentrations, coating, painting, and electronic industries [23], to evaluate the applicability of the CA electrospun mats with AC for the removal of VOCs. Most previous research studies using electrospun mats with AC have focused on energy applications, such as supercapacitors, solar cell, batteries, etc. [24-26]. These techniques require intensive energy for carbonization in electrospun polymer fibers to produce carbon nanofibers, while the fabrication technique proposed in this study can be simply applied to produce the AC-impregnated mats without carbonization. To our knowledge, this is the first demonstration of AC-powdered, impregnated, electrospun mats, using a mixture solution of AC powder and CA that also enhances their applicability in human mask and filter development.

\section{Experimental}

\subsection{Materials}

CA ( $\mathrm{Mn}=30,000 \mathrm{~g} / \mathrm{mol})$, AC (100 mesh particle sizes), and N, $\mathrm{N}$-dimethyl acetamide, were purchased from Sigma Aldrich (USA). Acetone and N, N-dimethyl acetamide (DMAC) were purchased from Samchun Chemicals (Republic of Korea). Additionally, AC and CA were used in polymer solutions at different proportions of AC. CA and AC were dissolved in a solvent of acetone (67\%) and dimethyl acetamide (DMAC) (33\%).

\subsection{Preparation of Polymer Solution and Synthesis of Fiber Mats Using Electrospinning}

AC was prepared in compositions of $5 \%, 10 \%$, and $15 \%$ with respect to the proportion of CA. Specifically, AC $(0.1 \mathrm{~g}, 0.2 \mathrm{~g}$, $0.3 \mathrm{~g}$ ) and CA (1.9 g, $1.8 \mathrm{~g}, 1.7 \mathrm{~g})$ were respectively dissolved in a combined solution of acetone (7.6 g) and DMAC (3.8 g). The prepared solution was added in a syringe to draw fibers. The fibers were collected on an aluminium foil collector which was placed at a distance of $210 \mathrm{~mm}$ near the needle tip. The applied voltage was $24.1 \mathrm{kV}$ and the flow rate was controlled at $0.02 \mathrm{~mL} / \mathrm{min}$ with the use of a syringe pump (Pump 11 Elite, Harvard Apparatus) up to $6 \mathrm{~h}$. At the end of electrospinning, the electrospun mat was kept in a vacuum oven at $140^{\circ} \mathrm{C}$ for $3 \mathrm{~h}$ for removing the solvents and moisture. Fig. S1 shows the color changes after the impregnation of AC. Polystyrene (PS, $1 \mathrm{~g}$ ) was dissolved to produce $20 \mathrm{wt} \%$ of dimethylformamide (DMF) solution during stirring at $50^{\circ} \mathrm{C}$ for $2 \mathrm{~h}$. Similarly, a PS electrospun mat was produced by applying the voltage of $30 \mathrm{kV}$ with a flow rate of $0.02 \mathrm{~mL} / \mathrm{min}$.

\subsection{Measurement of VOCs Adsorption Capacity Using QCM}

QCM was used to detect micro changes in the physical properties of the thin layers deposited on the crystal surface. A thin quartz crystal plate with metal electrodes deposited on the plate was the active element of the QCM. The voltage applied between the electrodes resulted in shear deformation within the quartz crystal owing to the piezoelectric properties and crystalline orientation of the quartz. QCM is useful in measuring the gas solubility in polymers and has a reversible nature in real time monitoring [27]. Furthermore, the reusability of the piezoelectric crystal is also one of the most important benefits of QCM. Sauerbery's equation provides a linear relationship between the resonant frequency shift of QCM and the mass attached on the electrode surface [28].

Before each adsorption capacity measurement, the electrospun mat was dried in a vacuum oven for $3 \mathrm{~h}$ to remove solvent and moisture. The prepared mats were attached to a gold-plated electrode 


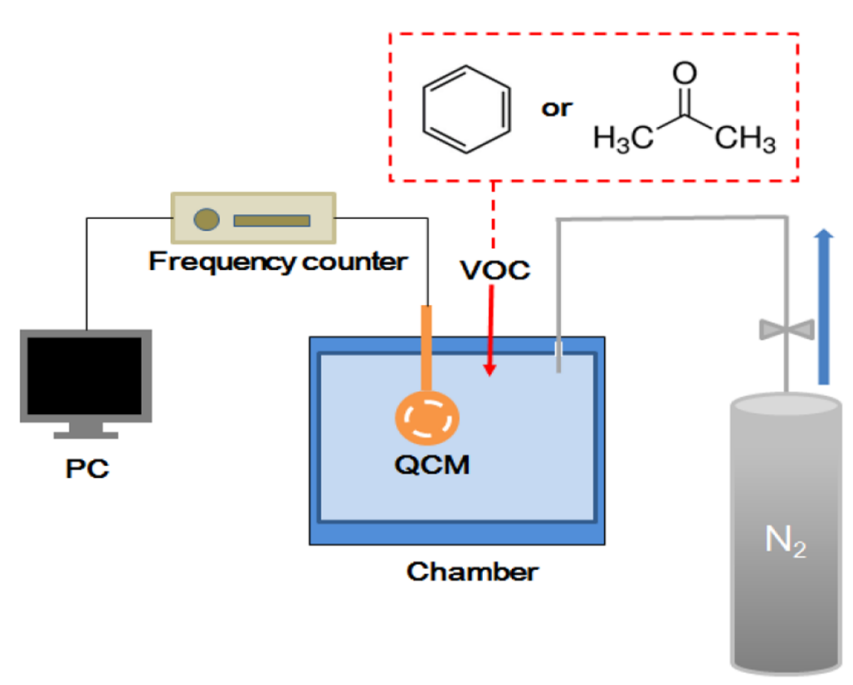

Fig. 1. VOCs measurement system using QCM.

so that it could be maintained in a vertical position inside a glass chamber to allow the measurements of the mass changes which occurred on the surface and the electrode following the placement of the sample in the sealed glass chamber (Fig. 1). Remained impurities and moisture in the glass chamber were further removed in the presence of flow of nitrogen gas until steady state was achieved, which was monitored on a PC connected to the QCM. In this experiment, $0.15 \mathrm{~mL}$ of a solution containing benzene, acetone, or dichloromethane in a single component was injected into the chamber which had a volume percent of 100 ppmv based on the volume of the glass chamber $(1,500 \mathrm{~mL})$. Three injections (with a volume percent of $100 \mathrm{ppmv}$ each) were conducted to measure an adsorption capacity until steady state was achieved in each step. The QCM detector can measure the adsorbed and desorbed VOCs on the samples in real time based on frequency changes. The adsorption capacity for each step was determined from the maximum adsorbed amount when the adsorption graph reached a plateau. The reported adsorption capacity was normalized by the weight of the electrospun mat. Comparative studies were conducted based on an adsorption capacity of acetone, benzene, and dichloromethane, at isothermal conditions $\left(30^{\circ} \mathrm{C}\right)$ for VOCs concentrations of 100, 200, and 300 ppmv, in an atmospheric pressure using a temperature-controlled water bath (Daihan Scientific Co., Ltd., Model WB-6). Desorption behaviors for the VOCs were studied by purging $\mathrm{N}_{2}$ gas at $30^{\circ} \mathrm{C}$ and by changing temperatures from 30 to $40^{\circ} \mathrm{C}$ when steady state reached 300 ppmv during adsorption.

\subsection{Measurement of Surface Area Using BET}

Surface structure characteristics of the electrospun mats with ACs were determined by the Brunauer-Emmett-Teller (BET) method using the BELSORP-Mini-II BET equipment (M/s Microtrac BEL Co., Japan). Samples were pretreated at $140^{\circ} \mathrm{C}$ for $2 \mathrm{~h}$ in vacuum to remove moisture and impurities. The specific surface area of BET was measured using BET plots using liquid nitrogen. Nitrogen gas was injected into a sample and a reference chamber to calculate the relative pressures during the monolayer deposition on the samples.

\subsection{Measurement of the AC Amount Using TGA}

Thermogravimetric analysis was carried out by a TGA instrument (N-1000 Scinco Co., Ltd.) to identify the composition of AC in the CA fiber membranes after the electrospinning process. The prepared mats were cut into very tiny pieces to fit into the measuring pan, and equal samples were measured for each proportion to ensure the accuracy of the results. Temperature gravimetric analyses of the samples were conducted in the presence of nitrogen at the flow rate of $50 \mathrm{~cm}^{3} \mathrm{~min}^{-1}$. The temperature was set at $600^{\circ} \mathrm{C}$ with the heating rate of $20^{\circ} \mathrm{C} \mathrm{min}^{-1}$ and the sample was held at $600^{\circ} \mathrm{C}$ for about an hour.

\section{Results and Discussion}

A pretreated sample was attached to the gold-plated electrode using heat so that it could be maintained in a vertical position inside the glass chamber to allow the measurements of mass changes on the surface. Nitrogen gas was purged inside the chamber to remove the dirt and moisture on the surface of the sample until steady state was attained. A volume of $0.15 \mathrm{~mL}$ of benzene, acetone, or dichloromethane, was injected into the chamber, and had a volume percent equal to 100 ppmv based on the volume of the glass chamber. Each 100 ppmv solution was injected three times after the steady state was attained. Fig. 2 shows the adsorbed amounts of acetone, benzene, and dichloromethane, on the electrospun mat (AC 15\%) as a function of time, which is obtained from the QCM system. From the adsorption graph, the adsorption capacities for each injection were calculated by taking the average value at steady state. Dichloromethane elicited faster adsorption kinetics than acetone and benzene owing to its smaller size. It took approximately $15 \mathrm{~min}$ for dichloromethane, 50 min for acetone, and $150 \mathrm{~min}$ for benzene to reach 95\% of the steady state adsorption amount at 100 ppmv. Accordingly, dichloromethane elicited faster adsorption kinetics than acetone and benzene owing to its smaller size. For the AC sample with a composition of $15 \%$, the adsorption of dichloromethane was $30 \%$ higher than acetone and $48 \%$ higher than benzene after the third injection.

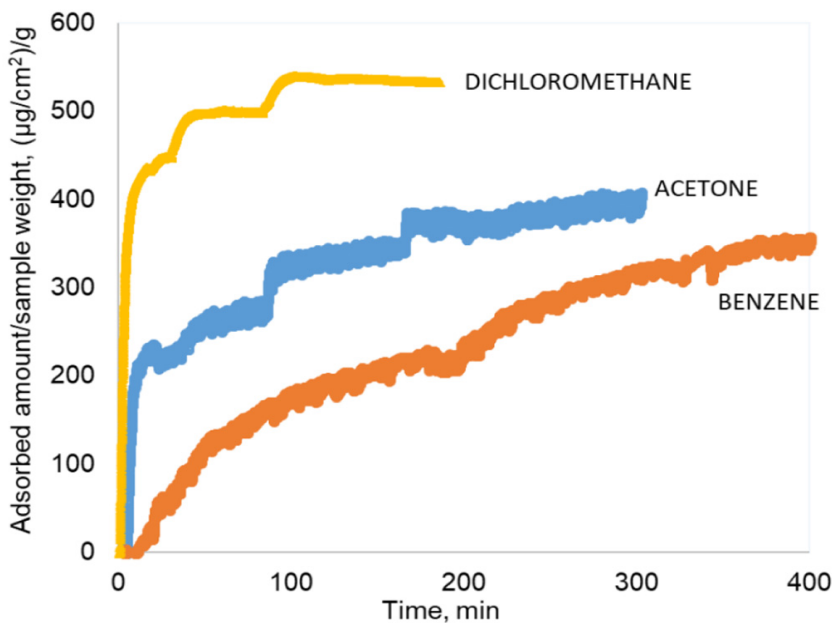

Fig. 2. Adsorption of acetone, benzene, and dichloromethane on AC with a composition of $15 \%$. 


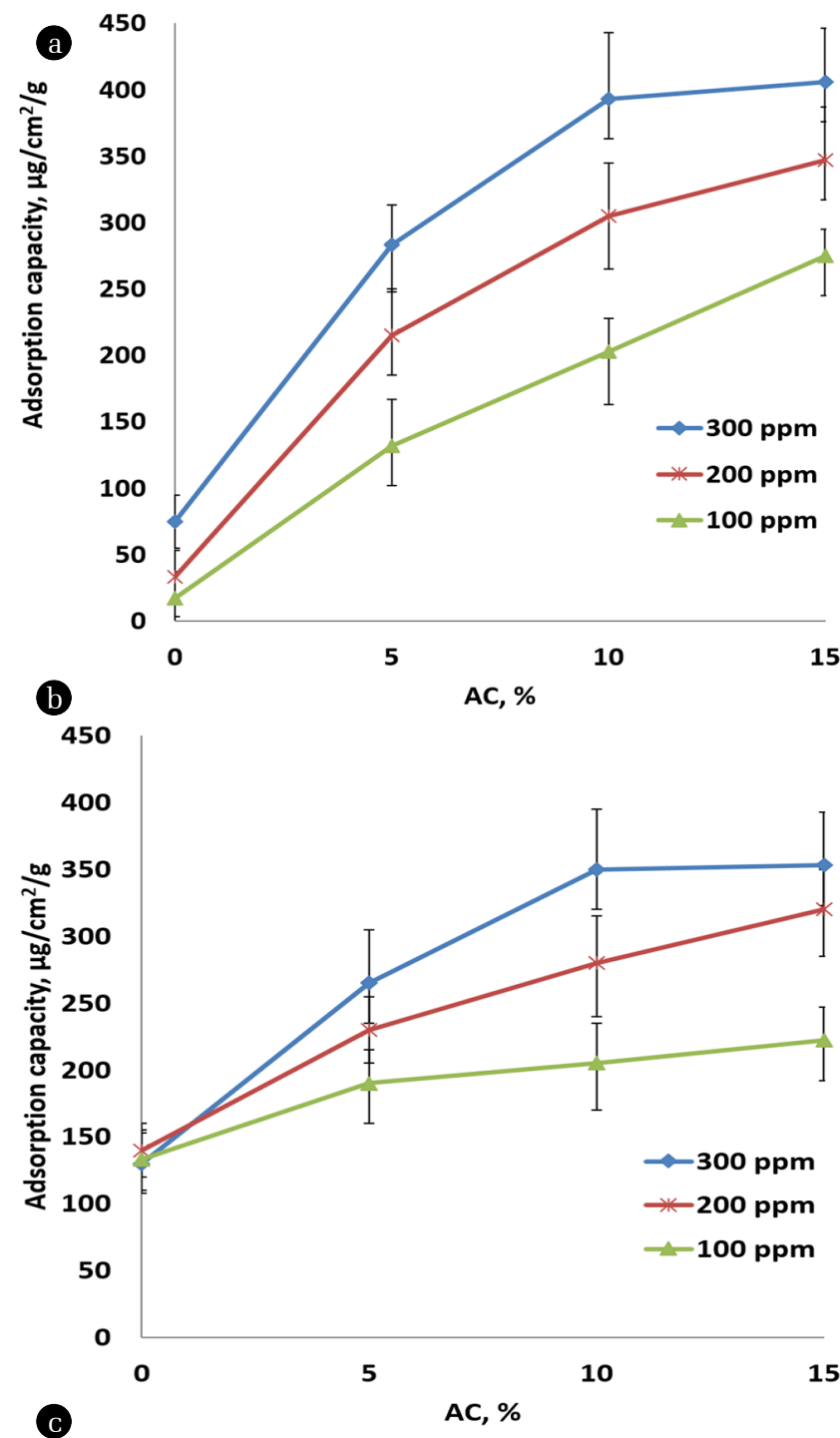

Fig. 3 shows the adsorption capacities for the injected VOCs on the electrospun mats with AC compositions of $0 \%, 5 \%, 10 \%$, and $15 \%$. There were no noticeable increases of adsorption capacities with the increase of injected amounts of VOCs for the electrospun mats without ACs, whereby physical adsorption of VOCs occurred on the surface of CA fibers in the mats. The adsorption capacities for acetone, benzene, and dichloromethane increased when AC amounts increased owing to the increased surface area and the pore volume of porous ACs. The capacity enhancement resulted from the additional adsorption of VOCs on the internal surfaces of the ACs in the AC-impregnated electrospun mats. For the electrospun mats without ACs, the adsorption capacities for dichloromethane were higher than acetone and benzene, while the adsorption capacity was enhanced further by the addition of ACs for dichloromethane. The mats synthesized with the ACs with compositions of $5 \%$ and $10 \%$ mats yielded a gradual increase in adsorption capacities, while the mat synthesized with the AC with a composition of $15 \%$ elicited the largest adsorption capacity after the 1st and 2nd injections, but it was more saturated after the 3rd injection. The highest enhancement of adsorption capacities was found for the AC with a composition of $5 \%$, while the graphs elicited a plateau for compositions higher than the AC of $10 \%$, especially for 300 ppmv injections. For the comparison of the adsorption capacities with other fiber adsorbents, a PS electrospun mat was produced using the electrospinning technique, and the VOC adsorptions were measured using the QCM instrument at $100 \mathrm{ppmv}$ and $30^{\circ} \mathrm{C}$. The AC impregnated CA electrospun mats showed higher adsorption capacities (Fig. 3) compared to the PS mat $\left(80 \mu \mathrm{g} / \mathrm{cm}^{2} / \mathrm{g}\right.$ for acetone, $90 \mu \mathrm{g} / \mathrm{cm}^{2} / \mathrm{g}$ for dichloromethane, $140 \mu \mathrm{g} / \mathrm{cm}^{2} / \mathrm{g}$ for benzene, see Fig. S2) owing to the increased surface area and the porosity induced by the addition of ACs.

To justify the AC impregnation in the electrospun mats, the surface areas were measured using the BET method where the adsorbed $\mathrm{N}_{2}$ monolayer was accounted to estimate the surface area and the pore volume [29]. Table 1 shows the characteristic analysis of the electrospun mats at different AC percentages. As the table results show, the specific surface area increases as the AC percentages increases in the CA electrospun mat. The mats with AC with a composition of $15 \%$ yielded the highest surface area, total pore volume, and the specifically adsorbed amount owing to the highest AC percentage, thereby resulting in the maximum adsorption capacities in the AC 15\% mats. Scanning electron microscopy (SEM) images were acquired to verify whether the ACs were dispersed within the fibers or whether they were combined inside the fiber materials. As shown in Fig. 4, the ACs were formed into droplet-like shape structures and were dispersed

Table 1. Surface Area, Pore Volume, and Adsorbed Amount of Liquid $\mathrm{N}_{2}$ for Electrospun Mats at Different AC Compositions

\begin{tabular}{lcc}
\hline \% of AC & $\begin{array}{c}\text { Specific surface area, } \\
\mathbf{m}^{\mathbf{2}} \mathbf{g}\end{array}$ & $\begin{array}{c}\text { Specific amount adsorbed, } \\
\mathbf{c m}^{\mathbf{3}} / \mathbf{g}\end{array}$ \\
\hline 0 & 14.23 & 12.765 \\
5 & 18.73 & 15.434 \\
10 & 19.62 & 16.231 \\
15 & 21.57 & 17.945 \\
\hline
\end{tabular}



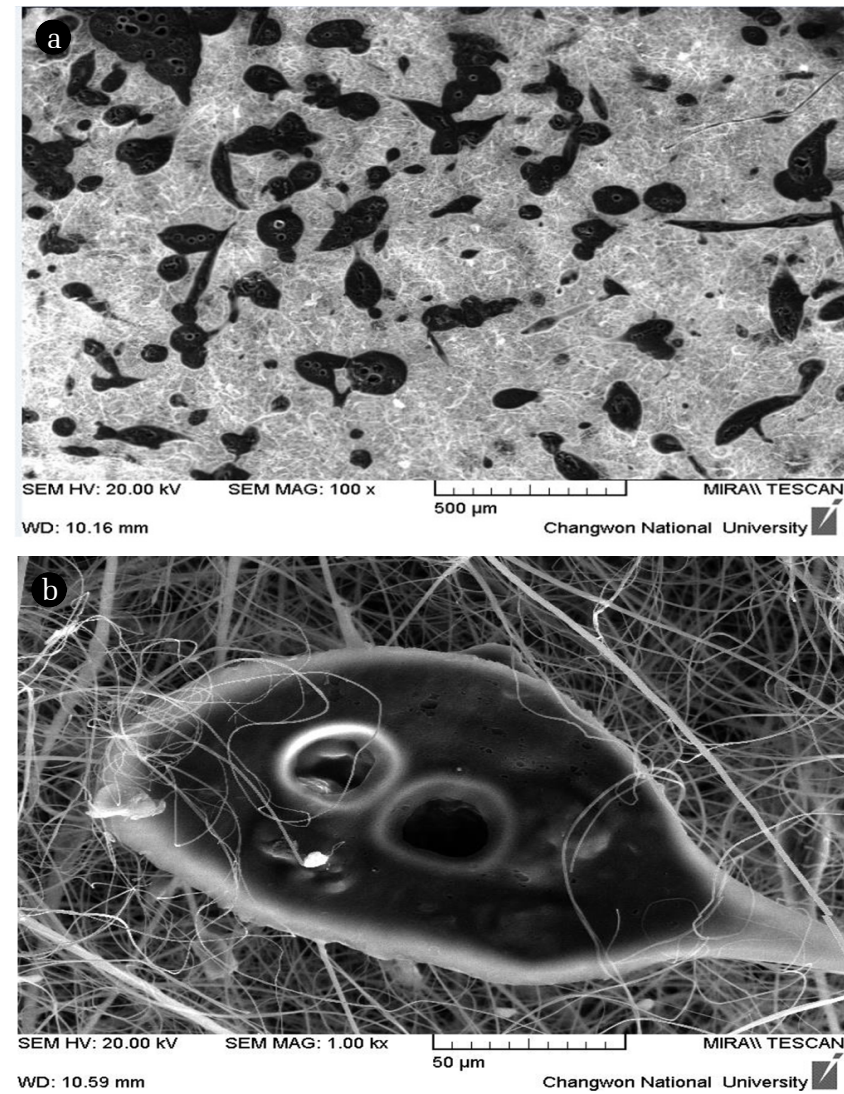

Fig. 4. SEM images for electrospun mats for an AC composition of $10 \%$. (a) CA electrospun mat at $100 \times$ magnification, and (b) $\mathrm{CA}$ electrospun mat at a $1,000 \times$ magnification.

within the fiber structures, thereby leading to enhanced adsorption properties owing to the increased interaction between VOCs and ACs compared to the case where ACs were impregnated in the fiber.

It is very important to predict the interaction between the solid adsorbent and the gaseous adsorbate for the analysis and design of the adsorption and separation in real life applications. Hence, it is vital to examine the experimental data with the appropriate equation. The adsorption data can be linearized by the Dubinin-Astakhov (DA) equation to overcome the problem faced in the characterization of the material. The DA equation includes additional parameters, which can linearize the adsorption data for a broad range of materials [30]. To explain the physical adsorption of gases on microporous materials, the DA equation was extensively used as follows

$$
a=a_{o} \exp [-(A / E) n]
$$

where $a$ is the adsorption capacity, $a_{o}$ is the limiting adsorption capacity, and $A$ is the Polanyi adsorption potential, which is described by the following equation

$$
A=R \operatorname{Rln}\left(P_{o} / P\right)
$$

where $R$ is the universal gas constant, $T$ is the equilibrium temperature, $E$ is the characteristic energy of the adsorbent-adsorbate system, $P_{o}$ and $P$ are the saturation vapor and equilibrium pressures, respectively, and $n$ is the Astakhov's exponent [4]. By plotting $\ln (a)$ vs. $\ln \left(P_{o} / P\right)^{n}$ we can obtain the results listed in the Table 2 .

Data obtained by fitting the DA equation shows that limiting the adsorbed capacities are well matched with the actual adsorbed amounts for each \% level increase in AC. The adsorption capacity increased with increases in the AC amount owing to the increased surface area of the ACs. This corresponded to the increasing characteristic energy of adsorption for each VOC in Table 2. In addition, the conducted analysis based on the DA equation showed that dichloromethane was strongly adsorbed on the AC impregnated CA mats compared to acetone and benzene. This inference was based on the higher characteristic energy of adsorption of dichloromethane compared to other compounds. We used TGA to characterize the AC compositions in the electrospun mats. Owing to the different degradation temperatures in the $\mathrm{AC}$ and the $\mathrm{CA}$, the

\begin{tabular}{|c|c|c|c|c|c|}
\hline Adsorbate & AC (\%) & $\begin{array}{l}\text { Astakhov exponent } \\
\text { (n) }\end{array}$ & $\begin{array}{l}\text { Actual adsorbed amount } \\
\qquad\left(\mu \mathrm{g} / \mathrm{cm}^{2} / \mathrm{g}\right)\end{array}$ & $\begin{array}{l}\text { Limiting adsorption } \\
\text { capacity, a。 }\left(\mu \mathrm{g} / \mathrm{cm}^{2} / \mathrm{g}\right)\end{array}$ & $\begin{array}{l}\text { Characteristic energy of } \\
\text { adsorption } E(\mathrm{~kJ} / \mathrm{mole})\end{array}$ \\
\hline \multirow{4}{*}{ Acetone } & 0 & 2.88 & 75 & 68 & 5.14 \\
\hline & 5 & 2.88 & 283 & 290 & 5.72 \\
\hline & 10 & 2.88 & 403 & 406 & 6.09 \\
\hline & 15 & 2.88 & 406 & 408 & 7.39 \\
\hline \multirow{4}{*}{ Benzene } & 0 & 2.88 & 165 & 165 & 4.25 \\
\hline & 5 & 2.88 & 255 & 255 & 4.35 \\
\hline & 10 & 2.88 & 350 & 335 & 4.37 \\
\hline & 15 & 2.88 & 352 & 350 & 4.41 \\
\hline \multirow{4}{*}{ Dichloromethane } & 0 & 2.88 & 245 & 258 & 7.47 \\
\hline & 5 & 2.88 & 391 & 405 & 8.63 \\
\hline & 10 & 2.88 & 431 & 435 & 8.28 \\
\hline & 15 & 2.88 & 534 & 541 & 11.28 \\
\hline
\end{tabular}

Table 2. Characteristic Energies and Limiting Adsorption Capacities Obtained by Fitting Based on the DA Equation 

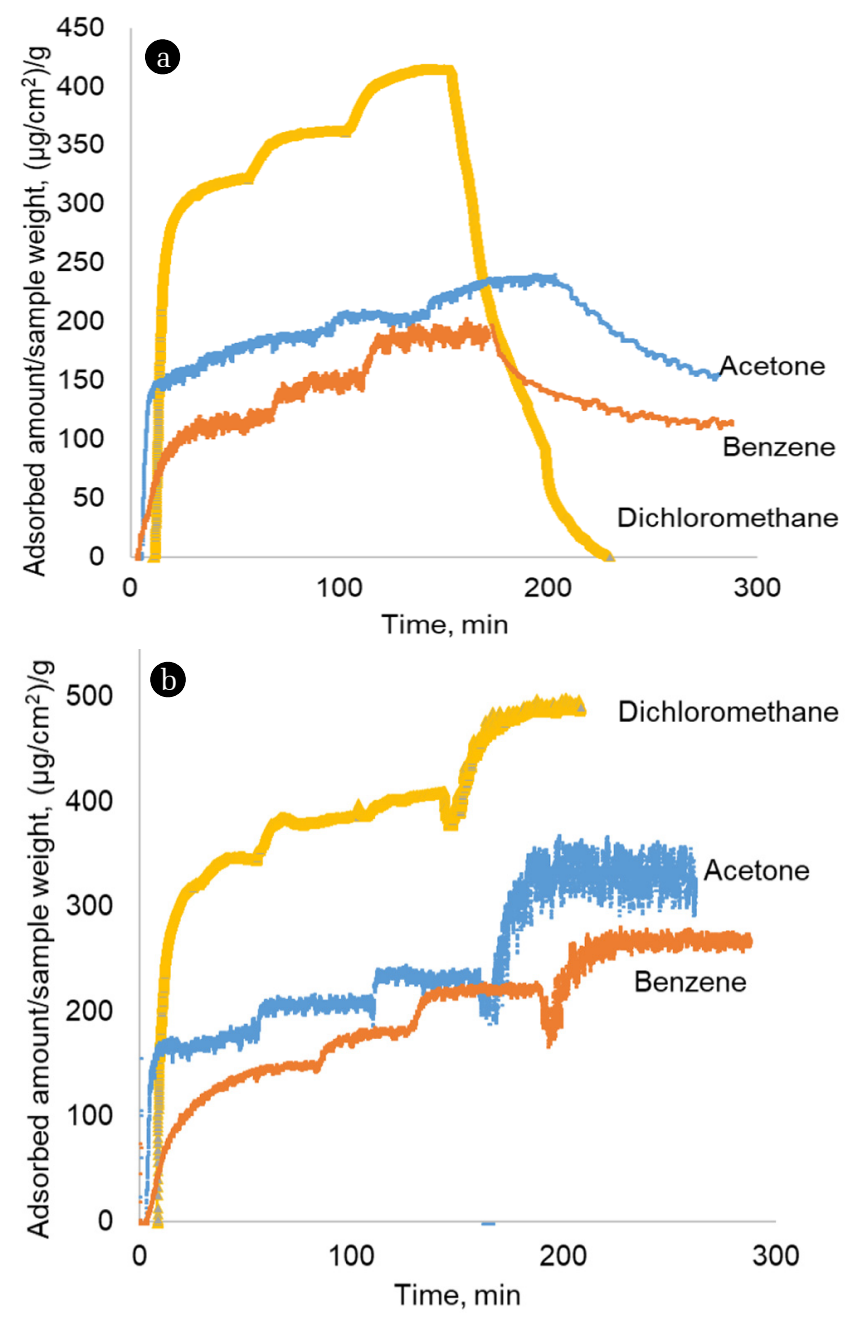

Fig. 5. Desorption behaviors of acetone, benzene, and dichloromethane by $\mathrm{N}_{2}$ gas purging (a) following a temperature increase of $40^{\circ} \mathrm{C}$, (b) for a mat with an $\mathrm{AC}$ composition of $5 \%$.

first large drop and the remaining \% weight corresponded to the $\mathrm{AC}$ and the CA amounts, respectively. Different weight percentages remained after the degradation of CA at temperatures above $320^{\circ} \mathrm{C}$ depending on the AC/CA composition. To calculate the AC compositions in the electrospun mats, dry sample weights were applied based on the subtraction of small weight drops from the total weight at the beginning of the heating process during the TGA operation (see Fig. S3-S5). It can be concluded from Table 3 that after the degradation of the CA at higher temperatures, the remain- ing amount of $\mathrm{AC}$ was equivalent to the actual impregnated amount of AC. The desorption behaviors of acetone, benzene, and dichloromethane, were analyzed by using two desorption methods of $\mathrm{N}_{2}$ gas purging and increases in the temperature, whereby the $\mathrm{N}_{2}$ gas was injected into the QCM chamber and temperature was increased from 30 to $40^{\circ} \mathrm{C}$, respectively, after the steady state at the 300 ppmv injection. When the temperature was increased, the VOCs evaporated and began to be adsorbed on the surface of the electrospun mats until steady state was achieved. Based on $\mathrm{N}_{2}$ gas purging, there were $35 \%, 42 \%$, and $100 \%$ desorbed for acetone, benzene, and dichloromethane, respectively, owing to the reduced concentrations of the VOCs (Fig. 5(a)). On the contrary, the adsorption amounts for acetone, benzene, and dichloromethane, increased when temperature increased possibly owing to the increase in vapor pressures, while the desorption was observed at the beginning of the temperature increase owing to the heat effects imposed on adsorption (Fig. 5(b)).

\section{Conclusions}

The AC-impregnated CA fiber mats had been developed with the use of the electrospinning technique. The adsorption capacities were effectively improved as the AC particles were aggregated and dispersed within the fibers rather compared to the case where they were incorporated in the fiber materials. To analyze the adsorption and desorption behaviors, the QCM system was successfully applied to the electrospun mat samples, and showed the ability of measurements of the adsorption capacity and kinetics. Therefore, we expect that the QCM system would be used to characterize the adsorption and desorption properties as a function of time for various adsorbents, such as zeolite, MOF, and other porous materials. TGA experiments successfully demonstrated the impregnated amounts of the AC over CA. We demonstrated the opportunity of $\mathrm{AC}$ as an adsorption enhancer. This was based on the fact that the adsorption capacities for VOCs increased with the increase of AC concentrations in accordance with the increase in the characteristic energy of adsorption analyzed based on the DA equation. Among the VOCs tested, the dichloromethane adsorption capacity was more enhanced compared to acetone and benzene when ACs were added on the base fiber mats. In the case of desorption based on temperature increases and $\mathrm{N}_{2}$ gas purging, the electrospun mats elicited opposing results. As the temperature of the bath increased, more VOCs were adsorbed on the surface of the mat, while the actual desorption took place in the dilute conditions with the $\mathrm{N}_{2}$ gas purging. In the $\mathrm{N}_{2}$ gas desorption process, dichloromethane was desorbed completely, while acetone and benzene were partially desorbed. For future studies, the mixture of AC

Table 3. TGA Analysis for AC/CA Samples (5, 10, and 15\%) Samples

\begin{tabular}{lcccc}
\hline $\begin{array}{l}\text { AC/CA } \\
\text { samples }\end{array}$ & $\begin{array}{c}\text { Sample weight with } \\
\text { impurities (mg) }\end{array}$ & $\begin{array}{c}\text { Dry sample weight without } \\
\text { impurities (mg) }\end{array}$ & $\begin{array}{c}\text { AC weight after CA } \\
\text { degradation (mg) }\end{array}$ & $\begin{array}{c}\text { \% of the AC in } \\
\text { electrospun mat }\end{array}$ \\
\hline $5 \%$ & 17.04 & 15.75 & 0.77 & 4.60 \\
$10 \%$ & 17.18 & 16.31 & 2.05 & 11.15 \\
$15 \%$ & 17.49 & 16.96 & 3.09 & 15.40 \\
\hline
\end{tabular}


and polymer solution can be directly electrospun to various supports, such as personal masks, air conditioning filters, and window screens, to greatly improve the removal efficiency of VOCs on the base filter.

\section{Acknowledgments}

This research was supported by the Basic Science Research Program through the National Research Foundation of Korea (NRF) funded by the Ministry of Education (\#NRF-2017R1C1B1002851) and a cooperative R\&D between Industry, Academy, and the Research Institute, funded by the Korean Ministry of SMEs and Startups in 2018 (Grant No. S2606715).

\section{Nomenclature}

a Adsorption capacity $\left(\mu \mathrm{g} / \mathrm{cm}^{2} \cdot \mathrm{g}\right)$

$a_{\text {o }} \quad$ Limiting adsorption capacity $\left(\mu \mathrm{g} / \mathrm{cm}^{2} \cdot \mathrm{g}\right)$

A Polanyi adsorption potential

E Characteristic energy of adsorption $(\mathrm{kJ} / \mathrm{mole})$

$\mathrm{n} \quad$ Astakhov's exponent

$P \quad$ Equilibrium pressure

$P_{o} \quad$ Saturation vapor pressure

$\mathrm{R} \quad$ Universal gas constant

$\mathrm{T}$ Equilibrium temperature

\section{References}

1. Dwivedi P, Gaur V, Sharma A, Verma N. Comparative study of removal of volatile organic compounds by cryogenic condensation and adsorption by activated carbon fiber. Sep. Purif. Technol. 2004;39:23-37.

2. Huang C, Song M, Gu Z, Wang H, Yan X. Probing the adsorption characteristic of metal-organic framework MIL-101 for volatile organic compounds by quartz crystal microbalance. Environ. Sci. Technol. 2011;45:4490-4496.

3. Das D, Gaur V, Verma N. Removal of volatile organic compound by activated carbon fiber. Carbon 2004;42:2949-2962.

4. Nugent P, Belmabkhout Y, Burd SD, et al. Porous materials with optimal adsorption thermodynamics and kinetics for $\mathrm{CO}_{2}$ separation. Nature 2013;495:1-5.

5. Fletcher AJ, Cussen EJ, Prior TJ, Rosseinsky MJ. Adsorption dynamics of gases and vapors on the nanoporous MOF material $\mathrm{Ni}_{2}$ (4,4'-Bipyridine $)_{3}\left(\mathrm{NO}_{3}\right)_{4}$ : Guest modification of host sorption behaviour. J. Am. Chem. Soc. 2001;123:10001-10011.

6. Chiang Y, Chiang P, Huang C. Effects of pore structure and temperature on VOC adsorption on activated carbon. Carbon 2001;39:523-534.

7. Kim K, Ahn H. The effect of the pore structure of zeolite on the adsorption of VOCs and their desorption properties by microwave heating. Microporous Mesoporous Mater. 2012;152: 78-83.

8. Yang K, Suna Q, Xue F, Lina D. Adsorption of volatile organic compounds by metal-organic frameworks MIL-101: Influence of molecular size and shape. J. Hazard. Mater. 2011;195:124-131.

9. Huang Z, Zhang Y, Kotaki M, Ramakrishna S. A review on polymer nanofibers by electrospinning and their applications in nanocomposites. Compos. Sci. Technol. 2003;63:2223-2253.

10. Carletto VA, Carletto RA, Mazzuchetti G. Experimental investigations on the multi-jet electrospinning process. J. Mater. Process. Technol. 2009;209:5178-5185.

11. Feng C, Khulbe KC, Tabe S. Volatile organic compound removal by membrane gas stripping using electrospun nanofiber membrane. Desalination 2012;287:98-102.

12. Shim WG, Kim C, Lee JW, et al. Adsorption characteristics of benzene on electrospun-derived porous carbon nanofibers. J. Appl. Polym. Sci. 2006;102:2454-2462.

13. Li Q, Xu Y, Wei H, Wang X. An electrospun polycarbonate nano fibrous membrane for high-efficiency particulate matter filtration. RSC Adv. 2016;6:65275-65281.

14. Scholten E, Bromberg L, Rutledge GC, Hatton TA. Electrospun polyurethane fibers for absorption of volatile organic compounds from the air. ACS Appl. Mater. Interfaces 2010;3: 3902-3909.

15. Han S, Rutledge GC. Thermoregulated gas transport through electrospun nanofiber membranes. Chem. Eng. Sci. 2015;123: 557-563.

16. Su CI, Shih JH, Huang MS, Wang CM, Shih WC, Liu YS. A study of hydrophobic electrospun membrane applied in seawater desalination by membrane distillation. Fiber. Polym. 2012;13:698-702.

17. Muhammad SK, Shaikh AR, Mohammad MH. Catalytic oxidation of volatile organic compounds (VOCs) - A review. Atmos. Environ. 2016;140:117-134.

18. Gupta VK, Verma N. Removal of volatile organic compounds by cryogenic condensation followed by adsorption. Chem. Eng. Sci. 2002;57:2679-2696.

19. Zhou Y, Zhou L, Zhang X, Chen Y. Preparation of zeolitic imidazolate framework-8/graphene oxide composites with enhanced VOCs adsorption capacity. Microporous Mesoporous Mater. 2016;225:488-493.

20. Liu P, Long C, Li Q, Qian H, Li A, Zhang Q. Adsorption of trichloroethylene and benzene vapors onto hypercrosslinked polymeric resin. J. Hazard. Mater. 2009;166:46-51.

21. Goss KU, Eisenrreich SJ. Adsorption of VOCs from the gas phase to different minerals and a mineral mixture. Environ. Sci. Technol. 1996;30:2135-2142.

22. Si P, Mortensen J, Komolov A, Denborg J, Møller PJ. Polymer coated quartz crystal microbalance sensors for detection of volatile organic compounds in gas mixtures. Anal. Chim. Acta 2007;597:223-230.

23. Xueyang Z, Bin G, Anne EC, Chengcheng C, Yuncong L. Adsorption of VOCs onto engineered carbon materials: A review. J. Hazard. Mater. 2017;338:102-123.

24. Xiaofeng Lu, Ce W, Frédéric F, Nicola P. Electrospun nanomaterials for supercapacitor electrodes: Designed architectures and electrochemical performance. Adv. Energ. Mater. 2017;7: 1601301.

25. Hongjiao N, Chi X, Wei Z, et al. Free-standing thin webs of activated carbon nanofibers by electrospinning for rechargeable 
Li- $\mathrm{O}_{2}$ batteries. ACS Appl. Mater. Interfaces 2016;8:1937-1942. 26. Vijayakumara E, Subramania A, Fei Z, Dyson PJ. High-performance dye-sensitized solar cell based on an electrospun poly(vinylidene fluoride-co-hexafluoropropylene)/cobalt sulfide nanocomposite membrane electrolyte. RSC Adv. 2015;5:52026-52032.

27. Kumar A, Brunet J, Varenne C, et al. Tetra-tert-butyl copper phthalocyanine-based QCM sensor for toluene detection in air at room temperature. Sensor. Actuat. B-Chem. 2015;210: 398-407.

28. Lu F, Lee HP, Lim SP. Quartz crystal microbalance with rigid mass partially attached on electrode surfaces. Sensor. Actuat. A-Phys. 2004;112:203-210.

29. Gaikwad S, Kim S, Han S. $\mathrm{CO}_{2}$ capture using amine-functionalized bimetallic MIL-101 MOFs and their stability on exposure to humid air and acid gases. Microporous Mesoporous Mater. 2019;277:253-260.

30. Huang C, Song M, Gu Z, Wang H, Yan X. Probing the adsorption characteristic of metal organic framework MIL-101 for volatile organic compounds by quartz crystal microbalance. Environ. Sci. Technol. 2011;45:4490-4496. 